94 Journal of Library Automation Vol. 2/2 June, 1969

\title{
APPENDIX II
}

\section{A PROPOSED UTILIZATION OF THE SUBRECORD DIRECTORY AND SUBRECORD RELATIONSHIP FIELDS IN THE PROPOSED AMERICAN STANDARD FOR A FORMAT FOR BIBLIOGRAPHIC INFORMATION INTERCHANGE ON MAGNETIC TAPE}

The following Appendix is not part of the proposed Standard but is included to illustrate a method for handling subrecords within a bibliographic record.

\section{Subrecord Directory}

A subrecord directory will be used when a bibliographic record consists of more than one subrecord. The subrecord directory, when present, will contain entries comprising a directory of the directory entries.

\subsection{Entries in Subrecord Directory}

The format of each entry in the subrecord directory is as shown:

\begin{tabular}{|c|c|c|c|c|}
\hline & TAG & & \multirow[t]{2}{*}{ LENGTH } & \multirow{2}{*}{$\begin{array}{l}\text { STARTING } \\
\text { CHARACTER } \\
\text { POSITION }\end{array}$} \\
\hline $\begin{array}{l}\text { TAG } \\
\text { ID }\end{array}$ & $\begin{array}{l}\text { TYPE-OF- } \\
\text { RECORD }\end{array}$ & $\begin{array}{l}\text { BIBLIOGRAPHIC } \\
\text { LEVEL }\end{array}$ & & \\
\hline & 1 & 2 & 3 & 7 \\
\hline
\end{tabular}

\subsubsection{Tag}

The tag is associated with a complete subrecord.

\subsubsection{Tag ID}

The tag ID is a data element consisting of one basic character used to differentiate tags for multiple subrecords describing bibliographic units which have the same type-of-record and bibliographic level codes (See 3.2.4 and 3.2.5).

1.1.1.2 Type-of-Record and Bibliographic Level When the subrecord does not describe a primary bibliographic unit, the type-of-record and bibliographic level are assigned as though it did. 


\subsubsection{Length of Subrecord Directory}

The length of that portion of the directory associated with the subrecord. (This value is always a multiple of twelve and when divided by twelve, equals the number of entries associated with the subrecord.)

\subsubsection{Starting Character Position}

The starting character position is that of the first entry in the directory which pertains to the subrecord. It is a five-digit decimal number relative to the first character of the bibliographic record.

\section{Subrecord Relationship Field}

A subrecord relationship field will be present if, and only if, a subrecord directory is present. The subrecord relationship field, when present, shall contain fixed fields which are used to indicate the relationships of subrecords to each other.

2.1 Relationship Fields

The format of each relationship field is as shown:

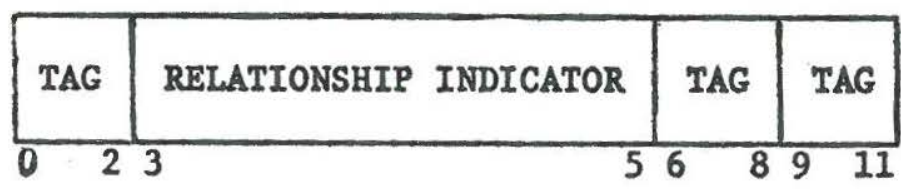

If a subrecord bears the same relationship to two subrecords, they may both be shown, otherwise the second tag field is padded with the padding character. There is no limit to the number of relationship fields or to the number of relationships which may involve a specific subfield. The relationship fields may be used to develop, and define tags for, hierarchies of subfields. One bibliographic record may contain no more than 64 subrecords with the same type-of-record and bibliographic level.

\subsubsection{Tag}

The tags in the subrecord relationship field have the same format as those in the subrecord directory.

2.1.2 Relationship Indicator

A relationship indicator is a data element consisting of three (3) basic characters used to indicate the relationship between subfields. 